\title{
GUNNING DOWN THE FOG: A TEST OF THE UNINTELLIGIBILITY AND \\ ILLITERACY HYPOTHESES ${ }^{1}$
}

Hugh P. Whitt

University of Nebraska - Lincoln

James C. Creech

University of Nebraska - Lincoln

Mid-American Review of Sociology, 1982, Vol. VIII, No. 1:39-49

Sociologists have often been criticized for their inability to make themselves understood. Talcott Parsons, in particular, has been singled out for his alleged incomprehensibility. As a consequence, his name has achieved legendary stature for more than his theoretical contributions. The present inquiry examines Parsons' writing style using the Gunning fog index of readability, finding that Parsons was indeed unintelligible as a writer. Moreover, it was discovered, serendipitously, that a postive feedback loop was operating (i.e., with one exception, Parsons became more unintelligible with each new book).

NOTE: A good writing style can considerably improve our ability to communicate ideas; we should always try to express ourselves as clearly as possible. But good style is no substitute for good ideas. Parsons' contributions to the discipline, whether we agree with them or not, shaped the development of sociology for many years. His ideas are his memorial.

Mills (1959:31) maintains that "one could translate the 555 pages of The Social System (Parsons, 1951) into about 150 pages of straightforward English." Going a step farther, he provides a translation in four paragraphs, claiming that they contain "all that is intelligible" in the monograph.

This is an extreme form of the "unintelligibility hypothesis," a frequently articulated but seldom explicitly formulated element of sociological folklore. Stated in a simplistic and 
non-technical manner, this hypothesis contends that sociologists, because of an overcommitment to using lengthy, convoluted sentences containing polysyllabic jargon expressions derived from an argot known only to the initiated, obfuscate the signalto-noise ratio of their attempts at written communication, thereby rendering their textual materials unintelligible to persons of normal or even above average intelligence (Cf. Cheek and Rosenhaupt, 1968). clearly.

More technically, it states that sociologists do not write

One hears the unintelligibility hypothesis from a wide variety of sources. Parsons seems to be a favorite target of first-year graduate students, but undergraduates tend to focus on the textbooks in their courses, while full professors lament the obscurity of the latest memo from their departmental chair. For some reason, advanced graduate students seem to think that the more unintelligible the prose in their dissertations, the better the quality of the writing. This may be a variant of the process of "identification with the aggressor" in which prolonged subjection to forced compliance with demands to read obscure authors leads the student to mimic the unintelligible styles of established authorities.

With specific reference to Parsons, Bruce Mayhew (1980: $352-353)$ points out that "(s)ome... have concluded that his works are incomprehensible. I agree with them.... Since I have not understood Parsons' work, I have no way knowing whether . . . anyone ... has fathomed Parsons' arguments."

Similarly, Edward Devereux (1961), in the preface to his summary of Parsons' theories, cautions the reader that

In the interests of communication... I shall... avoid becoming entangled in the peculiar subtleties and obscurities of Parsonian language. Parsons has been explaining his own theories in his own words these many years, but the evidence is rather impressive that he has not always succeeded in making himself understood.... At the risk of seeming 'unscholarly' I shall try to state as directly and simply as possible what it it is I think he has been saying (1961:2).
Moreover, Andreski (1972:60) cites Parsons as " $(t)$ he prime example of obscurity," maintaining that "he can make the simplest truth appear unfathomably obscure." Since every sociologist has at least had some contact with the unintelligibility hypothesis, no additional documentation of the literature need be offered.

One of the most powerful forms of hypothesis testing involves the "crucial test" of two or more mutually contradictory hypotheses. Fortunately, there is an alternative to the unintelligibility hypothesis which can be used in such a test. This is the well-known "illiteracy hypothesis." According to this view, which tends to be expressed by misunderstood grand theorists, authors defending their own work to publishers, and professors berating their students for their inability to grasp the perfectly obvious points made in the textbook, the problem lies with the reader rather than the writer. Typical expressions of the hypothesis are "If you can't understand this, you must be illiterate; it's perfectly clear to me," or, in the hands of an author whose paper has just been rejected for publication, "If only the reviewers had read the paper, they wouldn't have misinterpreted it so badly." Perhaps the clearest formal statement of the illiteracy hypothesis is the claim by Tyree et al. (1971:95) that sociologists "are, with blessed few exceptions, very nearly illiterate."

There is some indirect support for the illiteracy hypothesis in the downward trend of SAT and ACT scores over the last decade and in the widely reported phenomenon of grade inflation in the colleges. A careful search of the literature on the unintelligibility hypothesis and its competitor, the illiteracy hypothesis, reveals, surprisingly, that neither has been adequately tested. Mills' (1959) purported test of the unintelligibility hypothesis is flawed in several ways. The work of only a single author (probably an outlier on the intelligibility continuum) is examined, and no details of the procedure for sampling from Parsons' works or for the selection of specific passages from the single (and possibly non-representative) volume examined are provided. Further, Mills (1959) fails to provide a clear operational definition of "unintelligibility" which could be used in subjecting his analysis to replication. 


\section{METHOD AND DATA}

This paper presents a crucial test of the unintelligibility and illiteracy hypotheses. Such a test requires the use of readability formulas which may be unfamiliar to many sociologists. These techniques, however, have been employed for a variety of purposes. In educational research, readability measures have been used to assess the difficulty of textbooks intended for primary and secondary school students, while media researchers have employed them to ensure that television programs do not exceed certain minimal standards of comprehensibility (i.e., that programs requiring more than a sixth grade education for comprehension are automatically cancelled).

There is a long history of concern for the clarity of textual materials. The earliest attempt at an operational definition of "readability" was apparently Lively and Pressey's (1923) "weighted median index number" which combined "vocabulary range," "index of difficulty," and "zero-valued words" into a single readability formula. Since that time, there has been a proliferation of alternative measurements, all of which have in common the intent to provide "quantitative, objective estimates of the style difficulty of writing" (Klare, 1963:3). These instruments all map the same theoretical territory, so we have chosen to employ the Gunning "fog index" because the fog index has become something of a standard tool for analyzing textbooks and technical writing (Mullins, 1977), and a BASIC program has been developed recently which makes it widely available for users of personal computers (Nottingham, 1981).

Gunning (1968) developed the fog index as a measure of grade level required for understanding textual material. The index is computed in the following manner:

1. Select systematic samples of 100 words from the textual material. Begin the sample at the start of a sentence and do not end it in the middle of a sentence.

2. Divide the number of words by the number of sentences to obtain mean sentence length.
Gunning Down the Fog

3. Count the number of words of three or more syllables (excluding proper names) to obtain the number of "hard words."

4. Divide the number of hard words by the total number of words in the sample and multiply by 100 to obtain the percentage of hard words.

5. Add the mean sentence length and the percentage of hard words and multiply the result by .40 . The result is the fog index, which is interpreted as the number of years of formal education required for 75 percent comprehension of the textual material in a single reading.

In part of the analysis reported below, we have departed from Gunning's systematic sampling procedures. The materials tested are (1) the segments of The Social System (Parsons, 1951) reproduced by Mills (1959); (2) several books written by Parsons; and (3) Mills' (1959) translation of Parsons. In the case of items (1) and (3) the index was computed over the entire text. Systematic samples were used for the materials from Parsons.

Using the fog index as a criterion, the unintelligibility hypothesis will receive support if the grade level required for comprehension exceeds the educational attainment of the expected audience. On the other hand, if the grade level required for comprehension is equal to or less than the educational level of the audience, we must assume that any difficulty with the material supports the illiteracy hypothesis.

\section{FINDINGS}

Table 1 shows our calculations of the fog index for the textual materials described above. The segments from The Social System (Parsons, 1951) reproduced by Mills (1959) have a mean sentence length of 29.32 words; 21.12 percent of the words are hard according to Gunning's criterion. The value of the fog index is 20.18, indicating that slightly more than four years of graduate work is required to understand this material. A closer look reveals that the fog index varies considerably from 
Table 1

Components of the Fog Index in Samples from the Writings of Talcott Parsons (s.d.'s in parentheses)

\begin{tabular}{llcc}
\hline Source & $\begin{array}{c}\% \text { Hard } \\
\text { Words }\end{array}$ & $\begin{array}{c}\text { Words per } \\
\text { Sentence }\end{array}$ & $\begin{array}{c}\text { Fog } \\
\text { Index }\end{array}$ \\
\hline 1. Excerpts from The Social & 21.12 & 29.32 & 20.18 \\
System reproduced in Mills & $(3.41)$ & $(7.54)$ & $(3.03)$ \\
2. The Structure of Social & 21.69 & 24.73 & 18.57 \\
Action (1937) & $(2.45)$ & $(2.98)$ & $(1.41)$ \\
& & & \\
3. The Social System (1951) & 20.59 & 27.20 & 19.12 \\
& $(1.94)$ & $(7.89)$ & $(3.63)$ \\
& & & \\
4. Essays in Sociological & 22.81 & 34.29 & 22.84 \\
Theory (1954) & $(4.28)$ & $(3.95)$ & $(3.19)$ \\
& & & \\
5. Structure and Process in & 23.18 & 28.93 & 20.84 \\
Modern Societies (1960) & $(3.62)$ & $(6.66)$ & $(1.52)$ \\
& & & \\
6. Social Structure and & 22.30 & 30.89 & 21.28 \\
Personality (1964) & $(4.92)$ & $(8.68)$ & $(3.69)$ \\
\hline
\end{tabular}

paragraph to paragraph. At some points, his writing becomes readable for persons with little more than a college education. There are, for example, paragraphs with fog indexes of 16.02, 16.80 , and 17.97. But in between these are more difficult passages, including one that requires almost 28 years of formal education. The standard deviation of the fog index across paragraphs is 3.03 years. Assuming a normal distribution, approximately 16 percent of the paragraphs in Parsons require 23 or more years of education, or seven years of graduate work. This indicates that understanding the work as a whole (including the more difficult passages) is perhaps less easily accomplished than the overall index of 20.18 might suggest, and that a professional colleague might be justified in claiming that the problem is unintelligibility rather than illiteracy.

It might be objected that Mills' sample is chosen in such a way as to illustrate a point, and that the passages he uses are not representative of The Social System as a whole. In order to assess this possibility, a systematic sample of seven passages was drawn from the work using a random start. The results are shown in the third panel of Table 1 . For these passages, the overall fog index is 19.12-approximately one year of required education less than in the material reproduced by Mills (1959). The standard deviation is 3.63 years, and two of the sample passages require 24 or more years of education. We may conclude that while the passages chosen by Mills are slightly more unintelligible than the volume as a whole, they are nonetheless fairly representative of Parsons' writing style in The Social System.

A second possible source of bias in Mills' analysis is that The Social System may not be representative of Parsons' writings. There is evidence of this bias in Parsons' (1937) earliest book, The Strucutre of Social Action. There, Parsons (1937: vii-viii) explicitly acknowledges that "my father, President Emeritus Edward S. Parsons of Marietta College ... took upon himself the heavy burden of going through the whole manuscript in an attempt to improve its English style. Whatever readability an unavoidably difficult work may possess is largely to be credited to him."

By the time The Social System appeared, however, the elder Parsons was no longer available to translate his son's prose. This leads to the hypothesis that The Structure of Social Action should be less unintelligible than Parsons' later writings. To explore this possibility, seven passages were selected from The Structure of Social Action. The Gunning (1968) fog index for these passages are shown in the second panel of Table 1.

As expected, The Structure of Social Action is considerably less foggy than The Social System. Mean sentence length is 24.73 (s.d. $=2.98$ ), the percentage of hard words is 21.69 (s.d. = 2.45), and the fog index is 18.57 (s.d. = 1.41). Although, between 1937 and 1951, Parsons only increased the fog index by one-half year, the reading level required to understand about 84 percent of his passages increased by more than two and onehalf years. While the percentage of hard words remained constant (around 21) during this period, words per sentence increased dramatically after the Structure of Social Action. Apparently, 
Parsons' father improved the readability of the earlier book by breaking up lengthy sentences. The average sentence in The Structure of Social Action is 16 percent shorter than in The Social System (24.73 vs. 27.20).

Mills published The Sociological Imagination in 1959. He died in 1962. Therefore, he may be excused for not analyzing Parsons' later works, such as Social Structure and Personality (Parsons, 1964). However, Essays in Sociological Theory (Parsons, 1954) was available at the time, and any complete test of the unintelligibility hypothesis with respect to Parsons should have considered it. The fourth panel of Table 1 provides the evidence missing from Mills' inquiry.

The Essays are even more unintelligible than The Social System. Mean sentence length is 34.29 (s.d. $=3.95$ ), percentage of hard words, 22.81 (s.d. = 4.28), and the fog index, 22.84 (s.d. = 3.19). A possibly important trend emerges from a comparison of The Structure of Social Action (Parsons, 1937) The Social System (Parsons, 1951), and Essays (Parsons, 1954). Parsons' writing becomes more unintelligible with the passage of time. Note the sequence 18.57, 19.12, 22.84. Increased fogginess is due almost entirely to the use of longer and longer sentences. Polysyllables remain roughly constant at slightly more than 20 percent of the text.

This serendipitous finding suggests the hypothesis that there is a positive feedback loop operating in such a way as to increase Parsons' unintelligibility over time. As each new book made its appearance, his stature as a grand theorist increased, thereby motivating him in his next book to attempt to express even more complex thoughts in a single sentence. If this hypothesis is correct, we would expect the trend to continue beyond Essays.

Parsons' next book was Structure and Process in Modern Societies (Parsons, 1960). The mean sentence length is 28.93 (s.d. = 6.66), the percentage of hard words is 23.18 (s.d. = 3.62) and the fog index is 20.84 (s.d. = 1.52). Because Structure and Process is less foggy than Essays, the positive feedback hypothesis is not supported. Indeed, the pattern is interpretable in terms of a negative feedback process initiated by the publication of Mills' stinging critique of Parsons' writing style. This would imply that later books would become less and less foggy. To explore this possibility, we examined Social Structure and Personality (Parsons, 1964).

The mean sentence length of seven passages from Social Structure and Personality is 30.89 (s.d. = 8.68). The percentage of hard words is 22.30 (s.d. = 4.92), and the fog index is 21.28 (s.d. =3.69). This indicates that Mills' (1959) critique temporarily broke the positive feedback process. After the random disturbance to the system, however, the process resumed and later works became increasingly unintelligible.

\section{CONCLUSIONS}

An analysis of four volumes from the writings of Talcott Parsons reveals that the unintelligibility hypothesis (Mills, 1959) is to some extent correct. With the exception of The Structure of Social Action, which his father edited for style, Parsons' works are, as Mills maintains, likely to be unintelligible to beginning graduate students. At the same time, however, they should be within the grasp of seasoned professionals. But, on the other hand, there are passages which require at least 28 years of formal education. Stated differently, any reasonably literate Ph.D. can understand parts of Parsons, but comprehending his work as a whole requires an educational attainment far beyond the norm.

This paper has dealt with only one aspect of the unintelligibility and illiteracy hypotheses. In addition to their application to Parsons' writings, these hypotheses have been proposed in anecdotal form as relevant to other textual materials produced by sociologists. More research is needed to determine which hypothesis best applies to textbooks, departmental memos, and articles in sociological journals.

As a final note, it should be pointed out that even college freshmen should be able to understand Mills' (1959) translation of Parsons. Mean sentence length is 13.18 , percentage of hard words is 15.55 , and the fog index is 11.49 . On the other hand, 
the fog index of the second paragraph of this essay is 29.57 , which is even foggier than Parsons.

\section{FOOTNOTE}

1. We wish to thank J. Miller McPherson, David R. Johnson, Nicholas Babchuk, Andrea Tyree, Charles O'Conner and two anonymous reviewers for their comments on an earlier version of this paper. Partial support was provided to the second author from a National Institute on Aging predoctoral traineeship from the Midwest Council for Social Research in Aging.

\section{REFERENCES}

Andreski, S.

1972 Social Sciences as Sorcery. New York: St. Martin's.

Cheek, F.E. and M. Rosenhaupt

1968 "Are Sociologists Incomprehensible? An Objective Study," American Journal of Sociology 73:617-27.

Devereux, E.C., Jr.

1961 "Parsons' Sociological Theory." Pp. 1-63 in Max Black (ed.), The Social Theories of Talcott Parsons. Englewood Cliffs: Prentice-Hall.

Gunning, R.

1968 The Technique of Clear Writing. New York: McGraw-Hill.

Klare, G.R

1963 The Measurement of Readability. Ames: Iowa State University Press.

Lively, B.A. and S.L. Pressey

1923 "A Method for Measuring the 'Vocabulary Burden' of Textbooks." Educational Administration and Supervision 9:38998

Mayhew, B

1980 "Structuralism versus Individualism: Part 1, Shadow-boxing in the Dark." Social Forces 59:335-75.

Mills, C.W.

1959 The Sociological Imagination. New York: Oxford University Press.

Mullins, C.

1977 A Guide to Writing and Publishing in the Social and Behavioral Sciences. New York: Wiley.

Nottingham, $\mathrm{R}$

1981 "Fog Index." Creative Computing 7:152, 154.
Parsons, Talcott

1937 The Structure of Social Action. New York: Free Press.

1951 The Social System. New York: Free Press.

1954 Essays in Sociological Theory. New York: Free Press.

1960 Structure and Process in Modern Societies. New York: Free Press.

1964 Social Structure and Personality. New York: Free Press.

Tyree, A. et al.

1971 "The Dickensian Occupational Structure." Sociological Inquiry 41:95-105. 